\title{
Advanced methods in landslide modelling
}

\author{
Giulio Iovine • Denis Cohen
}

Received: 7 July 2014/ Accepted: 7 July 2014/Published online: 15 July 2014

(C) Springer Science+Business Media Dordrecht 2014

Dangerous phenomena threaten human settlements and infrastructures in many sectors of the Earth. Specific actions are required for proper risk management, starting from hazard identification to risk mitigation (including monitoring and early warning) and reduction. Aiming at evaluating risk conditions, the set of causal factors must first be identified; then, the evolution (in space and time) of a given phenomenon must be predicted, e.g. using modelling approaches. Potential damage should be assessed by considering the vulnerability of the elements at risk, including its expected variation in terms of social, environmental, and structural components. Total risk evaluations should provide supporting information for optimal selections of mitigation and/or reduction measures, based on expected impact scenarios.

Precious lessons inferred from past disasters can be combined with adequate planning of human settlements, thus minimizing future risks. Unfortunately, the zero risk option is often unrealistic but innovative approaches can be adopted to minimize the residual risks. These include integrated modelling and monitoring of hazardous phenomena, vulnerability evaluations and land use planning, knowledge dissemination and risk communication, and adoption of remedial measures. If an area is threatened by different types of phenomenon, the evaluation of the overall risk may become quite complex.

Several approaches for risk evaluation have been proposed in the past decades (Iovine 2013): on one side, qualitative and quantitative techniques have been tested against real case studies, at local or regional scales; on the other, modelling and sensitivity analyses have been employed, and real-time monitoring systems implemented to support early

\footnotetext{
G. Iovine $(\bowtie)$

CNR-IRPI (Italian National Research Council - Research Institute for Geo-Hydrological Protection), Cosenza, Italy

e-mail: giulio.iovine@irpi.cnr.it

D. Cohen

Department of Geological and Atmospheric Sciences, Iowa State University, 253 Science I, Ames, IA 50011, USA

e-mail: dcohen@iastate.edu
} 
warning procedures (cf. e.g. Iovine et al. 1996; Chiocchio et al. 1997; Iovine et al. 2006a, b, c; Crisci et al. 2008; Iovine 2008; Iovine et al. 2010a; Capparelli et al. 2012). In this regard, some examples have recently been discussed in guest-edited special issues of relevant scientific journals (Iovine et al. 2006a, b, 2007, Iovine and Sheridan 2009a, b; Parise and Iovine 2009; Iovine et al 2010b, c, 2012, 2013; Parise et al. 2012).

In the present special issue, a selection of studies covering a large spectrum of topics related to hazard evaluation and risk mitigation is presented, including protection systems, dynamic effects of infiltration, and susceptibility. One of the papers deals with sensitivity analyses; another focuses on the effects of protection devices; a third is concerned with modelling the effects of infiltration on landslide dynamics; the remaining four papers deal with hazard scenarios and susceptibility analyses.

In more details, J. Rohmer discusses the influence of landslide properties on timedependent predictions of landslide evolution. In the paper "Dynamic sensitivity analysis of long running landslide models through basis set expansion and meta-modelling", a principal component analysis is adopted and combined with metamodelling to reduce the output dimensionality such that each component can be interpreted as a dominant mode of variation in the overall structure of temporal evolution. An application to the La Frasse landslide is then proposed for investigation in terms of dynamic sensitivity analysis, relationships between surface horizontal displacements, and slip surface properties caused by pore pressure changes, by performing only a limited number of long running simulations.

In the paper "Analysis of rockfall risk on mountainside roads: evaluation of the effect of protection devices", Mignelli and co-workers start from stating that roads in mountainous areas are often exposed to rockfall hazard. To guarantee safety requirements, multidimensional design processes are needed, involving both public and private technicians. A risk management approach is then applied to the road infrastructure network of Valle D'Aosta to evaluate rockfall risk levels and reduction effects that can be obtained thanks to protection devices and by also including a comparative analysis of road accidents.

Martelloni and Bagnoli deal with "Infiltration effects on a two-dimensional molecular dynamics model of landslides". In their paper, a 2D model for deep landslides triggered by rainfall, based on interacting particles, is proposed. In the model, landslide activation depends on exceedance of two thresholds related to speed and to static friction; interparticle interactions are modelled in terms of attractive and repulsive effects, and particle positions are computed according to a molecular dynamics method; increasing pore pressure due to the rainfall are simulated using an infiltration scheme; viscosity is also considered in the dynamical equations of motion. Validation against real landslide events shows good agreement with model predictions.

Piegari and Di Maio deal with sources of heterogeneity in modelling, often relevant on various timescales and whose precise description requires a large amount of input data, in addition to notable simplifications. In the paper "Simulations of landslide hazard scenarios by a geophysical safety factor", the authors adopt a different approach to slope stability assessment by focusing on variations of geophysical properties. More specifically, starting from experimental resistivity data, a series of numerical simulations are performed to understand how spatial changes of soil resistivity may affect the size of unstable areas.

Roodposhti and co-authors apply a multi criteria decision-making technique, known as PROMETHEE II, combined with a fuzzy analytical hierarchy process, as a weighting technique to explore landslide susceptibility mapping. In the paper "PROMETHEE II and Fuzzy AHP: An Enhanced GIS-Based Landslide Susceptibility Mapping", the following factors are considered in the analyses: slope, aspect, distance to river, drainage density, 
distance to fault, mean annual rainfall, distance to road, and lithology. Validation of the proposed approach against real data from a study area in Iran shows quite good results.

In the paper "Spatial pattern of landslides in Swiss Rhone Valley", Tonini and coworkers analyse the spatial pattern of quaternary gravitational slope deformations and historical/present-day instabilities in the Swiss Rhone Valley, to test whether such events are clustered or randomly distributed. Their analysis uses Ripley's K-function with proper modification of the K-function for inhomogeneous point processes. The cluster behaviour among landslide events and between gravitational slope deformations and earthquakes are then analysed. As a result, the phenomena appear spatially clustered at well-defined distance ranges.

Finally, Iovine and co-authors employ a logistic regression approach to estimate shallow-landslide susceptibility in a sector of SW Calabria based on linear statistical relationships with a set of territorial variables and using two distinct sets of real events for model calibration and validation. In the paper "Shallow-landslide susceptibility in the Costa Viola mountain ridge (southern Calabria, Italy), with considerations on the role of causal factors", the "best set" of variables is identified by iteratively excluding one variable at a time and comparing ROC results. Through a sensitivity analysis, the role of each factor in predisposing shallow slope failures in the study area is then discussed.

As a whole, this special issue allows for an interesting glance on recent studies on risk evaluations. The presented studies shine a light on potentials and limits of the employed approaches. Standard approaches for model evaluation and testing-as discussed by D'Ambrosio et al. (2013)-are not so prevalent in the considered field of research as well as in the papers collected in the present issue, thus limiting immediate reliable applications of the proposed approaches to risk mitigation and reduction. However, such examples offer an interesting glimpse of the potential capabilities of future models.

\section{References}

Capparelli G, Iaquinta P, Iovine G, Terranova OG, Versace P (2012) Modelling the rainfall-induced mobilization of a large slope movement in northern Calabria. Nat Hazards 61(1):247-256

Chiocchio C, Iovine G, Parise M (1997) A proposal for surveying and classifying landslide damage to buildings in urban areas. In: Paul G Marinos (Ed), Proc. International Symposium on Engineering Geology and the Environment, Greek National Group of IAEG, 23-27 June 1997 (Atene, Grecia), 1 553-558

Crisci GM, Iovine G, Di Gregorio S, Lupiano V (2008) Lava-flow hazard on the SE flank of Mt. Etna (Southern Italy). J Volcanol Geoth Res 177(4):778-796

D’Ambrosio D, Spataro W, Rongo R, Iovine GGR (2013) Genetic algorithms, optimization, and evolutionary modeling. In: Shroder JF, Baas ACW (eds) Treatise on geomorphology, vol 2., Quantitative modeling of geomorphologyAcademic Press, San Diego, pp 74-97

Iovine G (2008) Mud-flow and lava-flow susceptibility and hazard mapping through numerical modelling, GIS techniques, historical and geoenvironmental analyses. In: Sànchez-Marrè M, Béjar J, Comas J, Rizzoli AE, Guariso G (Eds.) Proceedings of the iEMSs Fourth Biennial Meeting: International Congress on Environmental Modelling and Software, 7-10 July 2008, 3 1447-1460

Iovine G (2013) Some Considerations on Available Approaches to Risk Mitigation. Geol and Geosci 2(1), http://dx.doi.org/10.4172/jgg.1000e107

Iovine G, Sheridan MF (2009a) Special Issue 2007 in Natural Hazards on "Modelling and simulation of dangerous phenomena, and innovative techniques for hazard mapping and mitigation". Nat Hazards 50(3):409-411

Iovine G, Sheridan MF (2009b) Preface special issue 2006 in computers and geosciences on "Modelling and simulation of dangerous phenomena, and innovative techniques for hazard mapping and mitigation. Comput Geosci 35(5):869-870 
Iovine G, Parise M, Crescenzi E (1996) Analysis of slope instabilities in the central sector of the Dauno Apennine (in Italian). Memorie della Società Geologica Italiana 51:633-641

Iovine G, Petrucci O, Rizzo V, Tansi C (2006) The March 7th 2005 Cavallerizzo (Cerzeto) landslide in Calabria-Southern Italy. In: Culshaw M.G., Reeves H.J., Jefferson I. and Spink T. (Eds.), Engineering Geology for Tomorrow's Cities. Proc. 10th IAEG Int. Congress, IAEG2006-Nottingham, United Kingdom, 6-10 September 2006, paper \#785, p 12

Iovine G, Di Gregorio S, Sheridan MF (2006b) Preface. Hazard evaluation and mapping through modeling and simulations. Comput Geosci 10(2):159-160

Iovine G, Sheridan MF, Di Gregorio S (2006c) Guest editorial. Computer simulation of natural phenomena for hazard assessment. Comput Geosci 32(7):859-860

Iovine G, Di Gregorio S, Sheridan MF, Miyamoto M (2007) Preface. Modelling, computer-assisted simulations and mapping of dangerous phenomena for hazard assessment. Environ Model Softw 22(10):1389-1391

Iovine G, Pastor M, Sheridan MF (2010a) Preface. Modelling and simulation of dangerous phenomena, and innovative techniques for hazard mapping and mitigation. Phys Chem Earth 35(3-5):125-126

Iovine G, Lollino P, Gariano SL, Terranova OG (2010b) Coupling limit equilibrium analyses and real-time monitoring to refine a landslide surveillance system in Calabria (Southern Italy). In: Iovine G, Huebl J, Pastor M, Sheridan MF (Eds.) Special Issue on "Approaches to hazard evaluation, mapping, and mitigation". Nat Hazards Earth Syst Sci 10 2341-2354

Iovine G, Huebl J, Pastor M, Sheridan MF (2010c) Outcomes of the special issue on approaches to hazard evaluation, mapping, and mitigation. Nat Hazards Earth Syst Sci 11:2433-2436

Iovine G, Sheridan MF, Huebl J, Pastor M, Aubrecht C, Scheer S (2012) Preface. Innovative modelling approaches for disaster risk reduction. Phys Chem Earth 49:1-2

Iovine G, Aubrecht C, Glade T, Huebl J, Pastor M (2013) Editorial. Modelling of dangerous phenomena and innovative techniques for hazard evaluation and risk mitigation. Georisk 7(4):237-239

Parise M, Iovine G (2009) Preface to the special issue on "Innovative approaches for evaluating landslide hazard and risk". Geografia Fisica e Dinamica Quaternaria 32(2):179-181

Parise M, Iovine G, Reichenbach P, Guzzetti F (2012) Introduction to the special issue "Landslides: forecasting, hazard evaluation, and risk mitigation". Nat Hazards 61(1):1-4 